\title{
Retrato das famílias habilitadas para adoção no município de Volta Redonda
}

\section{Portrait of families qualified to adoption in Volta Redonda municipality}

\author{
1 Daniele Ribeiro do Val de Oliveira Lima Santa Bárbara val99@uol.com.br \\ 1 Dario Aragão Neto \\ 2 Wendel do Nascimento Valério
}

Docente do Centro Universitário de Volta Redonda, UniFOA.
Discente do curso Serviço Social do Centro Universitário de Volta Redonda, UniFOA.

\section{RESUMO}

A Lei 8069/90, a Lei 12010/09 e o Plano Nacional de Promoção, Proteção e Defesa de Crianças e Adolescentes à Convivência Familiar e Comunitária determinam que o Estado deve assegurar a convivência familiar de crianças e adolescentes, se não for possível em sua família natural, numa família substituta, que pode se constituir pela adoção, para que se evite a institucionalização. A avaliação dos pretendentes à adoção é uma das etapas de preparação psicossocial dos postulantes, prevista no Estatuto da Criança e do Adolescente, em seu parágrafo terceiro, artigo 50 . A responsabilidade dessa etapa do processo é da equipe auxiliar do Juiz, composta por assistente social e psicólogo. E qual o perfil das famílias que desejam a adoção? Não há estudos e pesquisas que caracterizem o perfil do adotante, ao contrário da multiplicidade de informações sobre o perfil de quem pode ser adotado. Este trabalho objetiva apresentar o perfil dos habilitados para adoção no município de Volta Redonda, construído após a análise das fichas cadastrais dos habilitados registrados no Cadastro Nacional de Adoção e da leitura dos relatórios e pareceres profissionais da equipe técnica da Vara da Infância e Juventude da Comarca da Volta Redonda.

\section{PALAVRAS-CHAVE}

habilitação para adoção; perfil família adotiva; estatuto da criança e do adolescente.

\begin{abstract}
Law 8069/90, Law 12010/09 and the National Plan for the Promotion, Protection and Defense of Children and Adolescents to Family and Community Living determine that the state should ensure family life for children and adolescents, if it is not possible in their natural family, in a foster family, which can be constituted by adoption, in order to avoid institutionalization. The evaluation of applicants for adoption is one of the stages of psychosocial preparation of candidates provided for in the Statute of Children and Adolescents in its third paragraph, Article 50. The responsibility of this stage of the process lies with the judge's auxiliary staff, consisting of a social assistant and a psychologist. But what is the profile of families wishing to adopt? There are no studies and researches that characterize the adopter's profile, unlike the plethora of information on the profile of those who can be adopted. This study aims to present a profile of qualified adopters in Volta Redonda, built after the analysis of the registration forms of those registered in the National Register of Adoption and after reading professional reports and opinions of the technical team of the Childhood and Youth Court of the District of Volta Redonda.
\end{abstract}

\section{KEYWORDS}

qualification for adoption; adopting family profile; child and adolescent statute.

\section{Como você deve citar?}

SANTA BÁRBARA, Daniele Ribeiro do Val de Oliveira Lima; NETO, Dario Aragão; VALÉRIO, Wendel do Nascimento. Retrato das famílias habilitadas para adoção no município de Volta Redonda. Cadernos UniFOA, Volta Redonda, $\mathrm{n}$. 29, p. 89-103, dez. 2015. 


\section{INTRODUÇÃO}

O presente trabalho é resultado parcial da pesquisa de iniciação científica intitulada "Quem somos nós? 0 perfil dos requerentes à adoção e das famílias adotivas no Município de Volta Redonda".

O Plano Nacional de Promoção, Proteção e Defesa de Crianças e Adolescentes à Convivência Familiar e Comunitária (2006) infere o dever do Estado em assegurar a convivência familiar de crianças e adolescentes expressando que, quando tais vínculos são enfraquecidos ou rompidos, deve-se garantir a constituição de novos vínculos familiares e comunitários, inclusive pelo instituto da adoção. O entendimento é que lugar de criança e adolescente é na família e, caso alguma situação de violação de direitos ocorra e impeça o convívio familiar, uma das opções à institucionalização é a colocação em família substituta mediante adoção.

A média anual de adoções, conforme o Conselho Nacional de Justiça, é 100 adoções por ano. A partir de 2013, o CNJ passou a disponibilizar o perfil desejado de criança a ser adotada, assim como divulgar o perfil das crianças que estão para adoção. Mas o perfil do pretendente a adotar ainda é desconhecido. Nesse contexto, emerge a curiosidade empírica e a necessidade técnica e profissional de conhecermos quem são as pessoas que se disponibilizam a constituir família e a exercer a maternagem e paternagem a partir da adoção.

Aqui entendendo paternagem de forma análoga à maternagem, conceito discutido por Chodorow (1990) como possibilidade de cuidar, de criar vínculos, de fortalecer afetos. Está voltada a uma dimensão emocional e sociocultural da relação mãe e filho. Nesse sentido, seria complementar (e em alguns casos oposta) a ideia de maternidade, que está fundada na capacidade biológica da procriação.

A pesquisa busca caracterizar dois perfis de grupo, aqueles habilitados à adoção de crianças e adolescentes e outro referente às famílias adotivas, isto é, o intuito é conhecer quem quer adotar e quem adota, pois variáveis diversas são impostas nesse processo de constituição familiar por filiação jurídica.

Posto isso, o objetivo deste trabalho se configura na promoção do diagnóstico comparativo sobre: 1) as famílias que postulam a adoção e são habilitadas e aquelas que conseguem adotar; 2) e na identificação, nos documentos legais e relatórios técnicos, dos procedimentos e critérios de elegibilidade utilizados pelos juristas, assistentes sociais e psicólogos para o deferimento ou não do direito à adoção.

Neste artigo, apresentamos a primeira etapa do trabalho, que é o perfil dos habilitados para adoção no município de Volta Redonda.

\section{METODOLOGIA}

O PIC é realizado a partir de dupla dimensão: teórica e empírica. Para tanto, a metodologia empregada combina abordagem quantitativa e qualitativa.

A incursão bibliográfica é utilizada como forma de qualificar o debate e eleger as categorias que direcionem a análise e problematizem os fatos. Como método, tomamos as fases da pesquisa bibliográfica sugeridas por Lakatos e Marconi (2003), que são a escolha do tema, a elaboração do plano de trabalho, a localização, a compilação, o fichamento, a análise e interpretação e, por fim, a redação. 
Em paralelo à discussão temática, a ida a campo viabilizou a análise de formulários, fichas e relatórios, com os quais produzimos dados estatísticos. Todos os procedimentos são registrados em diário de campo e os dados em planilhas para a confecção de gráficos.

O recorte cronológico da pesquisa sobre o perfil dos habilitados está compreendido entre 2009 (ano de aprovação da Lei 12010/2009, que regulamenta os procedimentos para colocação em família substituta) e 2013. Esclarecemos que devido ao tempo médio necessário para a avaliação psicossocial e processual dos habilitados, aqueles que entraram com pedido em 2014 ainda não tiveram seus processos finalizados. Assim, como margem de segurança, elegemos o ano de 2013 para a análise final, pois, nos processos finalizados entre 2014 e 2015, estão os pedidos de 2013.

\section{RESULTADOS E DISCUSSÃO}

As fichas cadastrais dos habilitados à adoção foram pesquisadas no site do Conselho Nacional de Justiça. Pela comarca de Volta Redonda, desde 2003, temos cadastro identificado. Apesar de nosso recorte cronológico ser a partir de 2009, traçamos um paralelo entre a quantidade de habilitados antes de 2009 e após 2009, pois como já dito, esse é o ano de aprovação de uma legislação regulamentadora dos processos de colocação em famílias substitutas.

Vimos que ao todo a comarca de Volta Redonda tem 158 cadastros ativos de habilitados à adoção. Surpreendentemente, 79 cadastros anteriores a 2009 e 79 posteriores a 2009. Isso sugere que, apesar da nova lei 12.010/09 ter buscado a maior agilização e melhor otimização dos procedimentos para a viabilização das habilitações e adoções, inclusive com maior clareza sobre os critérios para as ações, não houve aumento na demanda por pedidos de habilitação, logo, nessa comarca o reflexo da nova legislação para o aumento no pedido de habilitações não foi significativo.

Isso nos faz refletir sobre os critérios subjetivos na avaliação e sobre a cultural local na compreensão de família. Esse último aspecto não possível de ser dimensionado com esta pesquisa.

Gráfico 1 - Quantitativo de Habilitados Antes e Depois da Vigência da Lei 12010/09

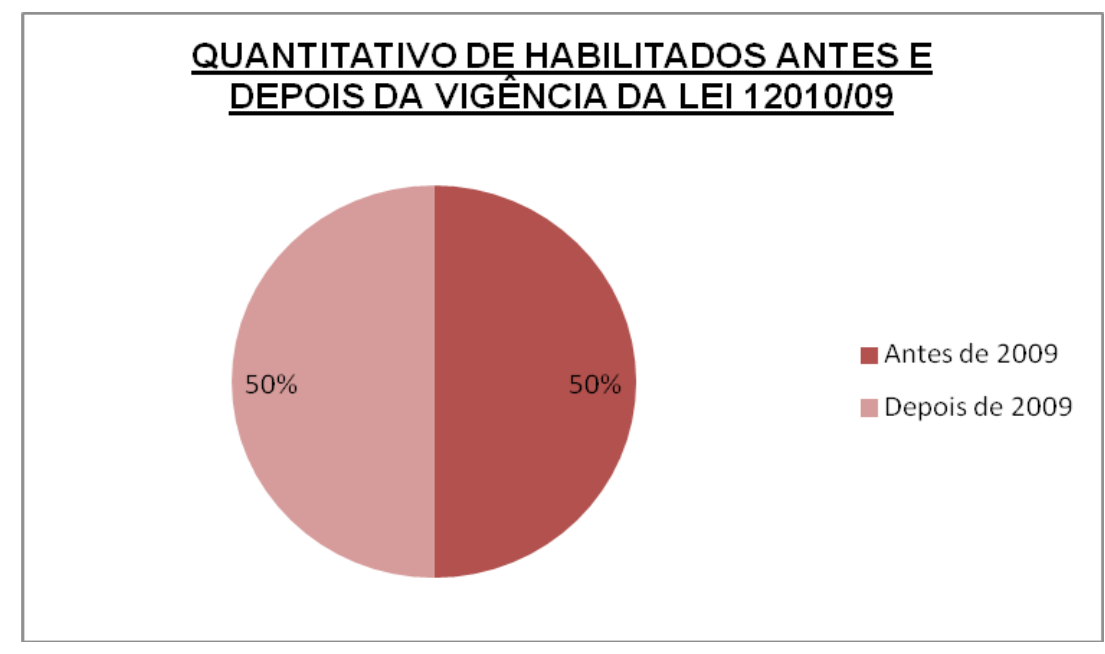

Fonte: $\mathrm{O}$ autor. 
As fichas cadastrais analisadas para caracterização do perfil dos habilitados seguiram a amostra dos $50 \%$ posteriores a 2009. Esclarecemos, contudo, que apesar da impressão e separação anual de todas as fichas, na ocasião do planilhamento das informações, identificamos a ausência de duas fichas. Tentamos localizá-las, mas sem sucesso. Destarte, a análise do perfil foi realizada sobre 77 fichas cadastrais.

\subsection{Configuração familiar}

Quanto à configuração da família, vimos que a composição familiar dos sujeitos habilitados à adoção de crianças e adolescentes retrata uma configuração familiar tradicional. São, na maioria, casais casados oficialmente que desejam ter de um a dois filhos. Na classificação dos arranjos familiares contemporâneos, são famílias que, mesmo que ao serem constituídas por filhos adotivos, corresponderão ao que chamamos de família nuclear burguesa, terminologia discutida por Badinter (1985).

Tabela 1 - Composição Familiar por Estado Civil

\begin{tabular}{ccc}
\hline & COMPOSIÇÃO FAMILIAR POR ESTADO CIVIL & PROCESSOS DE HABILITAÇÃO \\
\hline \multirow{2}{*}{2009} & CASAL CASADO & 17 \\
\cline { 2 - 3 } & SOZINHO SOLTEIRO FEMININO & 1 \\
\cline { 2 - 3 } 2010 & CASAL CASADO & 8 \\
\cline { 2 - 3 } & SOZINHO SOLTEIRO FEMININO & 1 \\
\cline { 2 - 3 } & SOZINHO SOLTEIRO MASCULINO & 1 \\
\hline \multirow{2}{*}{2011} & CASAL CASADO & 19 \\
\cline { 2 - 3 } & SOZINHO SOLTEIRO FEMININO & 1 \\
\cline { 2 - 3 } 2012 & CASAL CASADO & 13 \\
\cline { 2 - 3 } & CASAL EM UNIÃO ESTÁVEL & 1 \\
\hline \multirow{2}{*}{2013} & SOZINHO SOLTEIRO FEMININO & 10 \\
\cline { 2 - 3 } & CASAL CASADO & 1 \\
\hline
\end{tabular}

Fonte: 0 autor.

Observamos pela tabela que apesar de todos os avanços referentes ao debate sobre famílias e a forma como se organizam, ainda prepondera significativamente a ideia da família tradicional, e mesmo que a lei não impeça pessoas sozinhas de adotarem, elas são uma minoria.

Ademais, no contexto dessas fichas, não identificamos nenhum habilitado homossexual, até porque a ficha não prevê registro dessa informação. Como não realizamos análise dos relatórios técnicos ainda, seria possível neles encontrar o registro sobre a sexualidade do habilitado, contudo, ainda assim, esse é um dado que pode ser mascarado, tanto pela própria omissão da informação pelo sujeito que está sendo avaliado, pois ainda paira receio/mitos sobre a adoção homoafetiva, quanto pelo não registro do profissional desse dado, imbuído também de valores próprios ou de uma condução técnica que não avalie como pertinente a clareza da situação.

O gráfico, a seguir, ilustra o total de habilitados por composição familiar e estado civil. 
Gráfico 2 - Perfil dos Habilitados

\section{PERFILDOS HABILITADOS}

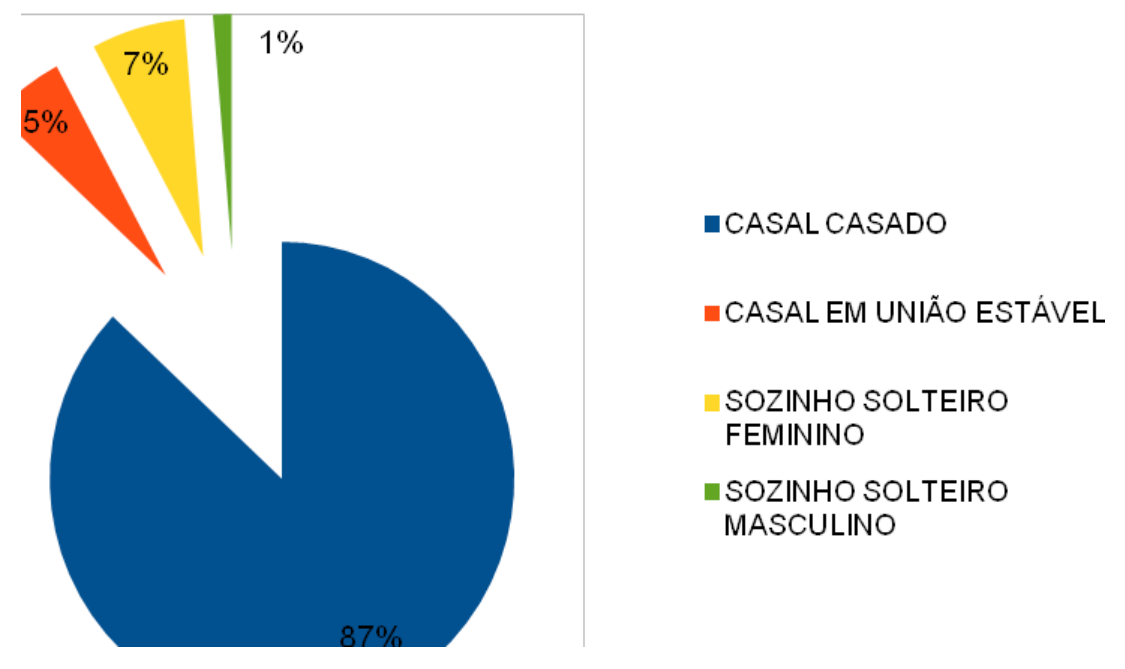

Fonte: $\mathrm{O}$ autor.

Vimos que $87 \%$ dos processos de habilitação se referem a habilitados casados. Contudo, se incluirmos os habilitados em união estável na configuração da família nuclear burguesa, chegaremos a 92\%.

\subsection{Naturalidade dos habilitados e das crianças desejadas:}

Esclarecemos que todos os habilitados têm nacionalidade brasileira e, para que algum estrangeiro figurasse nos registros, ele precisaria ser naturalizado brasileiro. Habilitação é diferente de adoção, logo, apesar de estrangeiros poderem adotar crianças ou adolescentes brasileiros, eles são habilitados no seu país de origem.

Também ressaltamos que o pedido de habilitação só pode ser realizado no Fórum de residência do requerente, logo, todos os habilitados residem em Volta Redonda. Entretanto, quanto à naturalidade, observamos muitos habilitados provenientes de outros municípios adjacentes a Volta Redonda e de estados da região sudeste, principalmente Minas Gerais.

Do total de 147 habilitados (contagem individual, abrangendo os casados e os solteiros), temos 90 deles naturais de Volta Redonda. Apesar da maioria ser natural e residir na Comarca de Volta Redonda, temos um índice importante de pessoas de outra naturalidade que residem na cidade. 
Gráfico 3 - Naturalidade

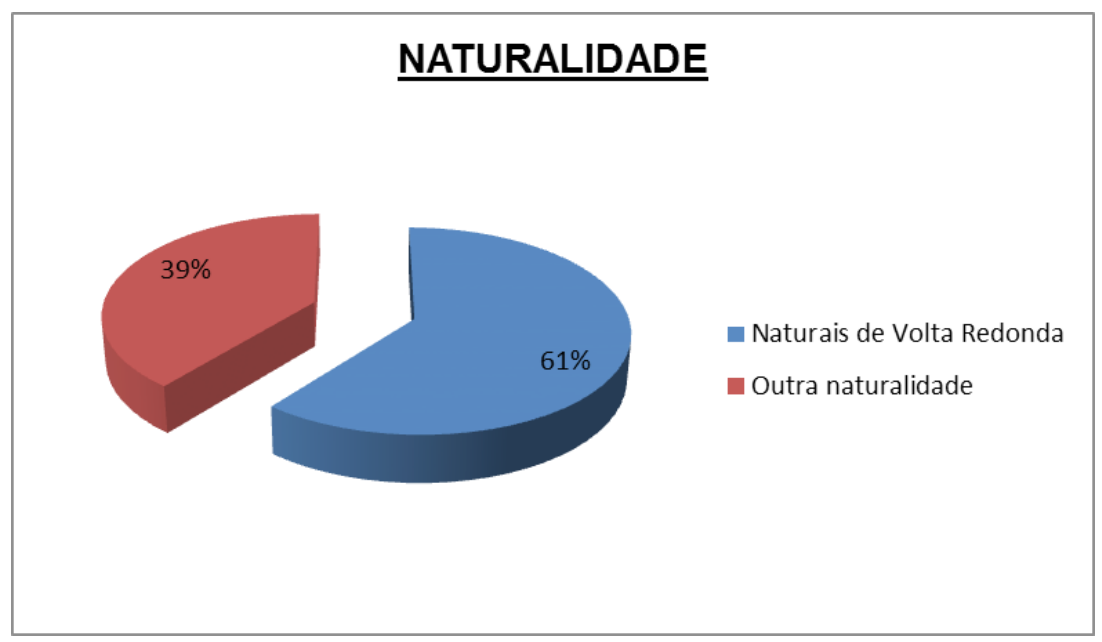

Fonte: 0 autor.

Diante disso, analisamos a aceitação dos habilitados quanto à origem/naturalidade do adotado. A expressiva maioria aceita crianças e adolescentes da região Sudeste, seguida da região Sul.

O Rio de janeiro é o estado que aparece na aceitação de todos os habilitados (100\%), seguido dos demais estados da região Sudeste e depois dos estados da região Sul, conforme tabela abaixo.

Tabela 2 - Estado de Origem

\begin{tabular}{ccc}
\hline ESTADO DE ORIGEM & NÚMERO DE PROCESSOS & ÍNDICE DE ACEITAÇÃO \\
\hline RJ & 77 & $100 \%$ \\
\hline SP & 68 & $88 \%$ \\
\hline MG & 67 & $87 \%$ \\
\hline ES & 59 & $76 \%$ \\
\hline SC & 39 & $50 \%$ \\
\hline PR & 37 & $48 \%$ \\
\hline RS & 35 & $45 \%$ \\
\hline
\end{tabular}

Fonte: 0 autor.

Por outro lado, os estados da região Norte são os que tiveram menor aceitação, quanto à origem da criança ou adolescente a ser adotado. Alguns estados do Nordeste e Centro Oeste também possuíram baixa aceitação. Destacamos que dessas regiões, o Distrito Federal foi o que mais apareceu como território de origem a ser aceito. Esclarecemos, porém, que a aceitação dos estados, exceto os das regiões Sudeste e Sul, apareceram nos casos dos processos cujos habilitados aceitam adotar crianças ou adolescentes de qualquer lugar. Isso significa que, nos casos em que há escolha de território de origem, os locais escolhidos são Sudeste e depois Sul. Aspectos regionais, culturais e étnicos podem explicar essa configuração. 


\subsection{Escolaridade}

No que se refere ao grau de escolaridade dos habilitados, identificamos um perfil de médio e alto grau de instrução.

Gráfico 4 - Escolaridade

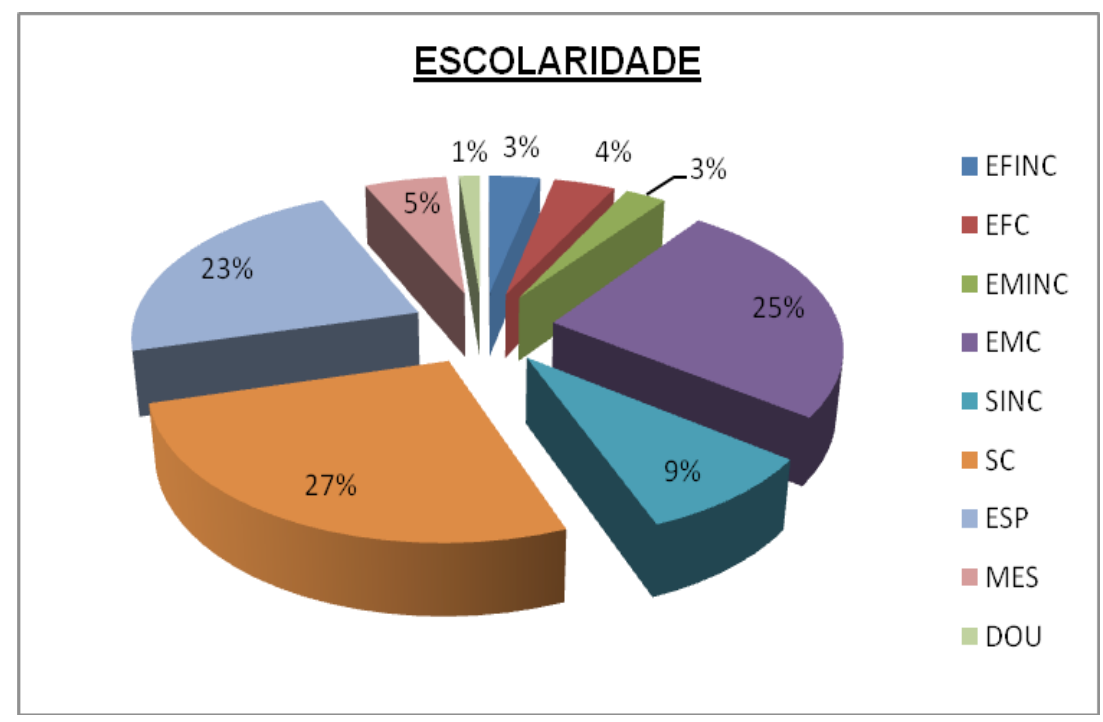

Fonte: 0 autor.

Se simplificarmos os indicadores, teremos $7 \%$ dos habilitados com ensino fundamental; $28 \%$, com ensino médio; e 65\%, com nível superior.

Isso nos instiga a formulação de algumas hipóteses, como a de que pessoas com mais potencial de esclarecimento/instrução tendem a regularizar as ações de adoções, enquanto que, nas famílias de menor índice de instrução, prepondera as relações de favorecimento para adoção pronta e circulação de crianças, aquilo que chamamos de adoção à brasileira, uma cultura enraizada de criação de filhos de terceiros.

Além disso, normalmente, quanto maior a escolaridade, maior a renda. Essa dupla caracterização de organização/inserção do indivíduo socialmente gera uma representação de que para adotar crianças é preciso ter condições, o que talvez seja um limite para a procura de pessoas mais pobres e/ou humildes pela adoção regular.

\subsection{Ocupação e Faixa Salarial}

O CNJ trabalha com a categoria ocupação e não profissão, o que permite o mapeamento do tipo de inserção sócio-ocupacional. 


\section{Gráfico 5 - Ocupação}

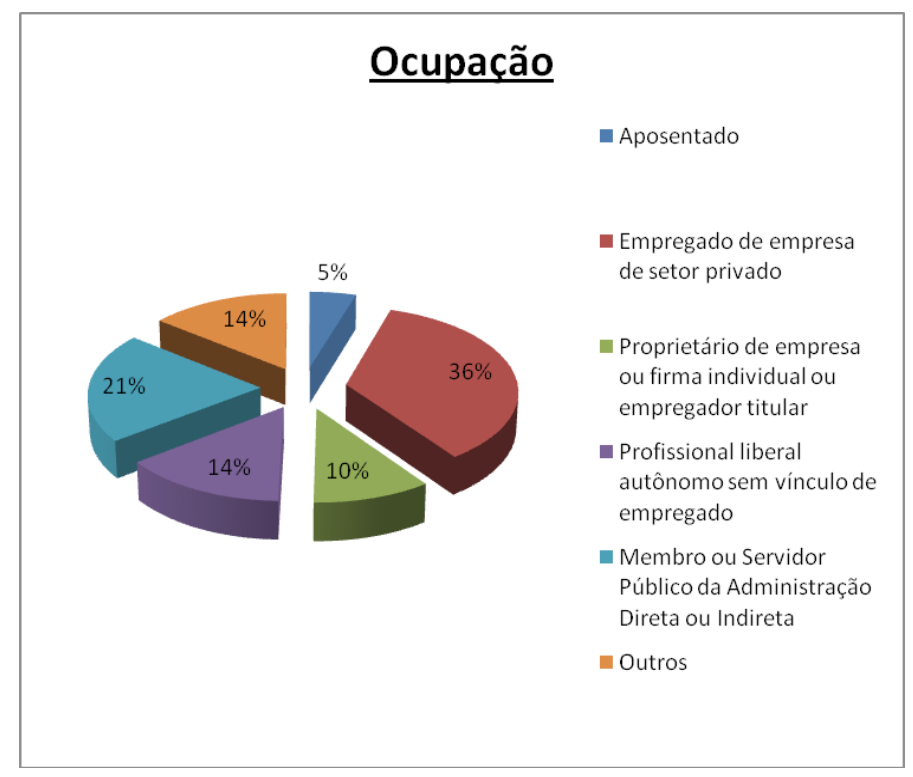

Fonte: 0 autor.

Como vimos no gráfico acima, a maioria dos habilitados está inserida no setor formal de trabaIho - considerando os vínculos público e privado. Já no que tange à renda, corrobora-se o sugerido no item escolaridade, de que, quanto maior a escolaridade, maior a possibilidade de renda. Cerca de $48 \%$ dos habilitados possuem renda individual igual ou superior a 5 salários mínimos. Entretando, a maior incidência salarial é na faixa de cinco a dez sálarios minimos (33\%) e a menor incidência é na faixa de vinte a trinta salários minimos (1\%).

Gráfico 6 - Renda

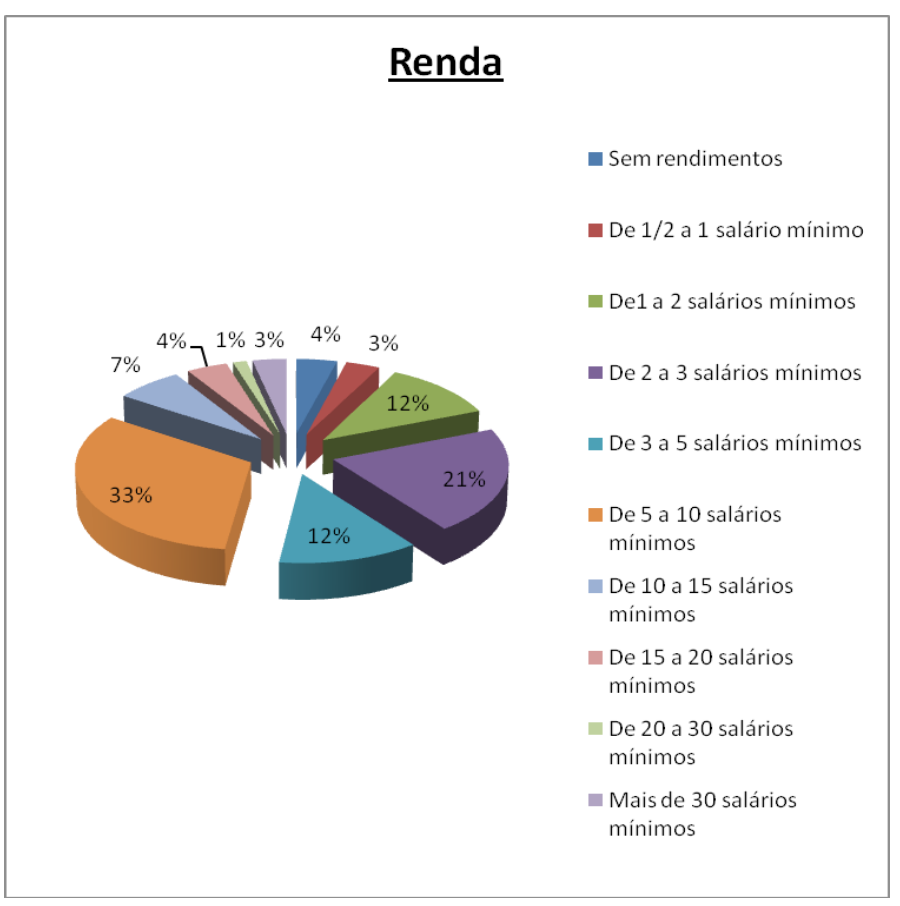

Fonte: 0 autor 
Gráfico 7 - Comparativo entre as Faixas Salariais

\section{Comparativo entre as faixas salariais}

Até 5 salários Mais de 5 salários

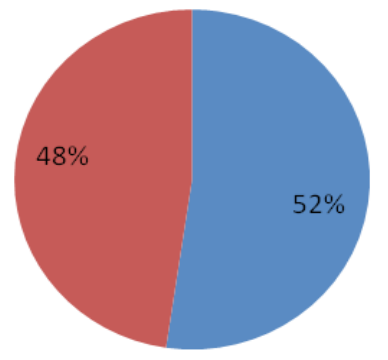

Fonte: 0 autor.

\subsection{Presença de filhos biológicos e/ou adotivos}

Pessoas que desejam adotar querem fazê-lo por diversos motivos. Tradicionalmente, a adoção é pleiteada por pessoas/casais que não podem ter filhos. Contudo, outras motivações acontecem e identificá-las é algo que só deverá ser possível com a análise dos relatórios técnicos ou dos processos.

A partir da análise dos cadastros, é possível desconfiar, porém, que na realidade dos habilitados de Volta Redonda não ter filhos foi a motivação principal para o pedido de habilitação, pois conforme tabela abaixo, a maioria significativa dos habilitados não possuem filhos biológicos, destes, a maior parte é mulher.

Tabela 3 - Quantidade de Filhos Biológicos

\begin{tabular}{lcc}
\hline & \multicolumn{2}{c}{ FILHOS BIOLÓGICOS } \\
\cline { 2 - 3 } & SIM & NÃO \\
\hline MULHER & 07 & 69 \\
\hline HOMEM & 19 & 53 \\
\hline TOTAL COM FILHOS & 26 & 122 \\
\hline TOTAL SEM FILHOS & & $83 \%$ \\
\hline ÍNDICE & $17 \%$ &
\end{tabular}

Fonte: 0 autor.

Um dado interessante de destacar é que alguns habilitados já possuíam filhos adotados. 
Tabela 4 - Quantidade de Filhos Adotivos

\begin{tabular}{ccc}
\hline & \multicolumn{2}{c}{ FILHOS ADOTIVOS } \\
\cline { 2 - 3 } & SIM & NÃO \\
\hline MULHER & 01 & 75 \\
\hline HOMEM & 03 & 69 \\
\hline TOTAL COM FILHOS & 04 & 144 \\
\hline TOTAL SEM FILHOS & & $97 \%$ \\
\hline ÍNDICE & $3 \%$ &
\end{tabular}

Fonte: $\mathrm{O}$ autor.

Vimos com esses números que a não maternidade é superior a não paternidade.

Não foi identificado casos em que o mesmo habilitado que tenha filho biológico também tinha adotivo.

\subsection{Idade média dos habilitados}

Pessoas de 30 a 49 anos constituem $84 \%$ dos habilitados. A faixa etária dos 30 a 39 anos fica apenas $2 \%$ à frente da faixa de 40 a 49 anos. Tal mapeamento indica a geração dos anos 70 como aquela que mais aparece entre os habilitados.

Gráfico 8 - Média de Idade de Habilitados

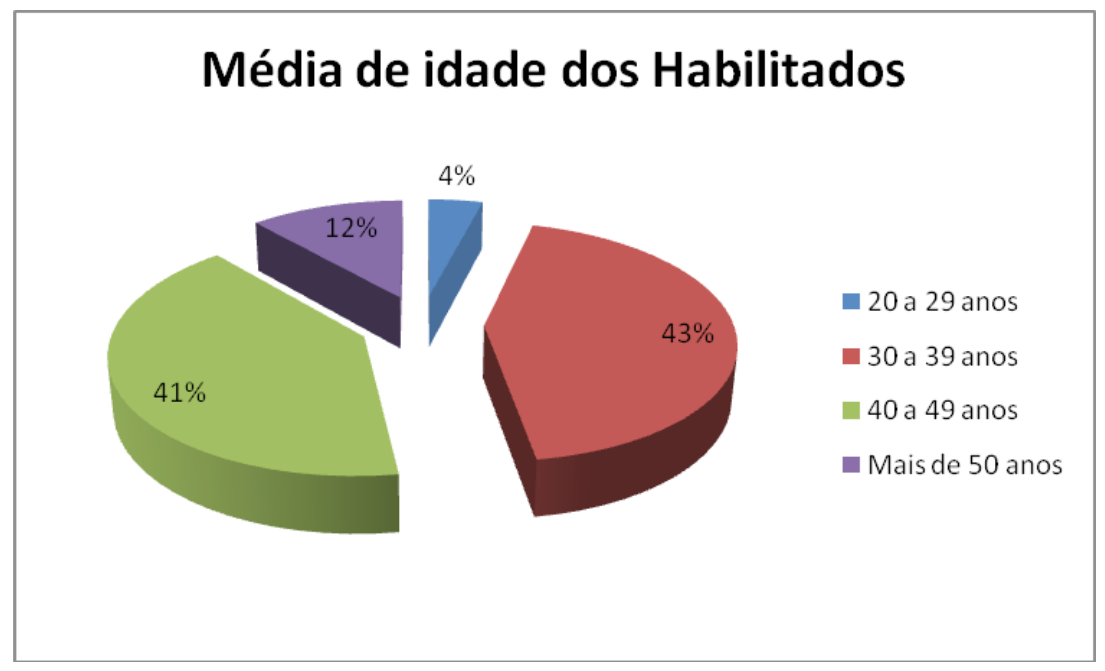

Fonte: $\mathrm{O}$ autor.

$\mathrm{Na}$ faixa etária destacada, cruzando o resultado de escolaridade e renda, podemos sugerir que, após maior estabilidade no mercado de trabalho e estabilidade financeira, abra-se a possibilidade da adoção. Outra possibilidade, porém, é que antes da adoção os casais podem tentar outros métodos para engravidar (inseminação e/ou fertilização) e, não conseguindo, optam por adotar. 


\subsection{Cor autodeclarada dos habilitados}

A identificação por cor de uma pessoa é sempre algo complexo e, muitas vezes, polêmica. Cor é diferente de etnia, normalmente se refere à cor da pele.

Os habilitados, nesta pesquisa, se declaram, em expressiva maioria, da cor branca. Somando os que se declaram negros e pardos, chegamos a $27 \%$ dos habilitados, nem a metade do número dos que se declaram brancos.

Gráfico 09 - Cor Auto Declarada

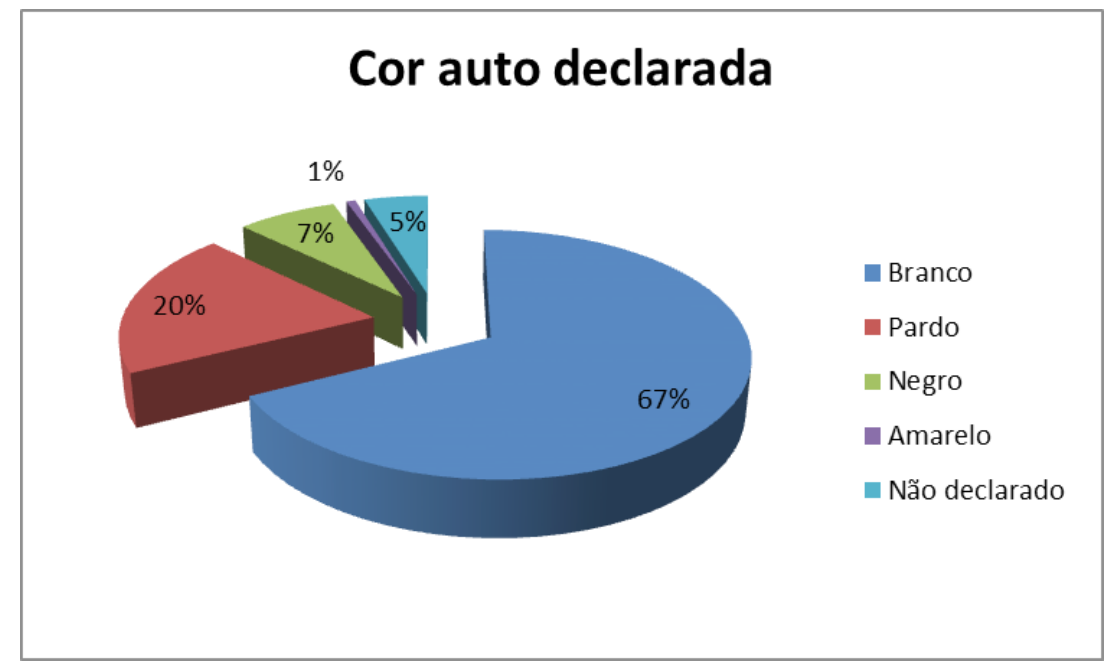

Fonte: $\mathrm{O}$ autor

Esse gráfico nos sugere algumas reflexões, como a questão da cor poder ser pensada pelo prisma do branqueamento. Além disso, vimos que os habilitados têm ocupações e renda salarial boas, o que também pode sugerir que a "elite é branca" e a "pobreza é preta", pois a maioria dos habilitados com renda salarial alta se autodeclaram brancos, tendência nos dados estatísticos em geral.

\subsection{Tempo médio de relação dos casais habilitados}

Observamos que os casais há pouco tempo juntos são os que menos estão entre os habilitados para adoção. Isso pode sugerir que eles aguardem a estabilidade da relação para iniciarem o projeto maternidade/paternidade, como também pode sugerir um tempo maior de investimento na gestação natural, antes de iniciarem o projeto de adotarem. 
Gráfico 10 - Tempo Médio de União de Casais Habilitados

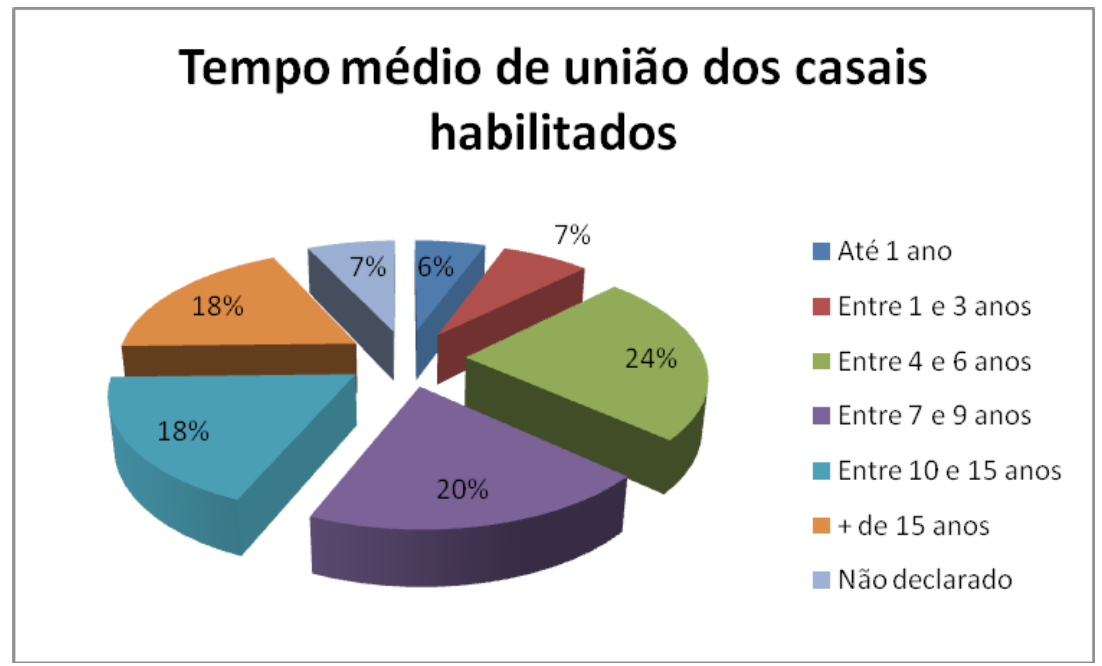

Fonte: $\mathrm{O}$ autor.

A maior incidência está no tempo médio de relação entre 4 e 6 anos, mas destacamos que as relações com mais de 10 anos chegam a $36 \%$ dos habilitados.

\subsection{Tempo médio para o deferimento da habilitação}

O processo de habilitação para adoção possui etapas pré-determinadas de execução. 0 rito burocrático apresenta uma dimensão que tem a ver com os ritos administrativos dos processos e uma dimensão de análise técnica dos profissionais auxiliares do Juízo, que são os assistentes sociais e os psicólogos.

Observamos, conforme quadro abaixo, que alguns processos duraram até mais de dois anos para serem concluídos, o que é justificado administrativamente pela pendência de documentos ou pela desistência e posterior retomada do processo. 0 tempo médio para haver o deferimento do pedido é de cerca de 7 a 12 meses, na maioria.

Tabela 4: TEMPO MÉDIO PARA HABILITAÇÃO

\begin{tabular}{ccccccc}
\hline TEMPO & $\mathbf{2 0 0 9}$ & $\mathbf{2 0 1 0}$ & $\mathbf{2 0 1 1}$ & $\mathbf{2 0 1 2}$ & $\mathbf{2 0 1 3}$ & TOTAL \\
\hline Até 6 meses & 3 & 0 & 3 & 3 & 1 & 10 \\
\hline 7 a 12 meses & 11 & 5 & 10 & 12 & 9 & 47 \\
\hline 13 a 18 meses & 2 & 3 & 3 & 2 & 1 & 11 \\
\hline 19 a 24 meses & 2 & 0 & 1 & 0 & 0 & 3 \\
\hline Mais de 24 meses & 0 & 3 & 3 & 0 & 0 & 6 \\
\hline TOTAL & & & & & & 77 \\
\hline
\end{tabular}

Fonte: $\mathrm{O}$ autor.

Se considerarmos a junção dos períodos até 1 ano, 1 a 2 anos e mais de 2 anos, temos uma configuração de tempo favorável, pois $74 \%$ dos processos levam até um ano para serem concluídos. 
Consideramos que não parece haver morosidade ou burocracia no correr do processo, mas sim, o respeito aos cuidados necessários para a elaboração de um estudo e parecer social e psicológico dos habilitados, que envolve participação em grupos, entrevistas e visitas domiciliares.

Gráfico 11 - Tempo Médio para a Sentença de Deferimento da Habilitação

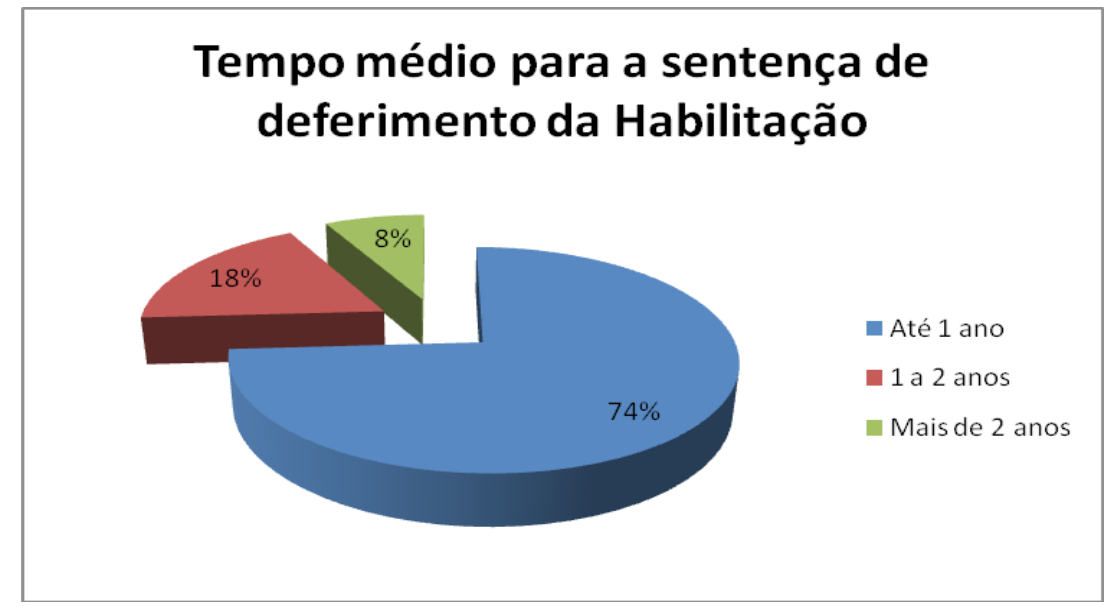

Fonte: $\mathrm{O}$ autor

É preciso destacar, porém, que, mesmo com a sentença deferida, isso não significa que os habilitados sejam automaticamente liberados para a adoção, pois a sentença precisa ser transitada em julgado e, após, ainda é preciso que seus processos sejam inseridos no Cadastro Nacional de Adoção.

0 tempo médio de espera da sentença deferida até a inclusão no $\mathrm{CNJ}$ é de até 12 meses, mas quase $50 \%$ dos processos são incluídos em até 6 meses. Contudo, algumas datas estão em branco e outras com erro de digitação, principalmente nos processos abertos no ano de 2012. Logo, não temos um dado fidedigno para esse tempo médio.

Gráfico 12 - Tempo Médio após Sentença para a Inclusão no CNJ

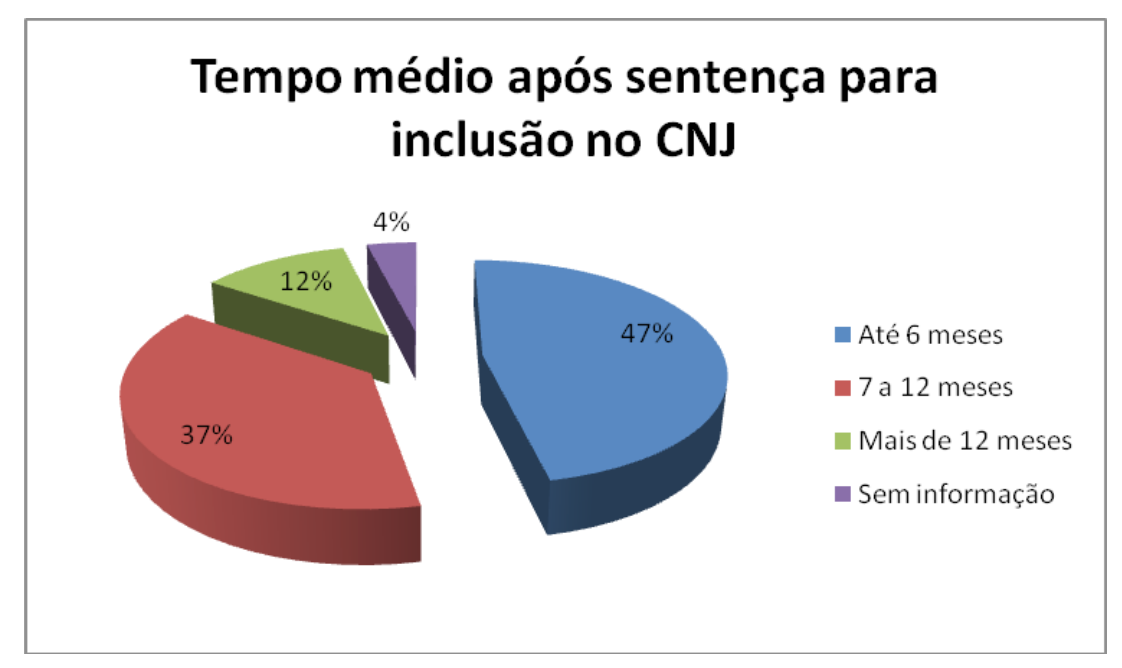

Fonte: $\mathrm{O}$ autor 


\section{CONCLUSÃO}

A caracterização do perfil dos habilitados para adoção na Comarca de Volta Redonda nos traz parâmetros importantes para o debate conceitual de família.

Os números nos mostram que há uma tendência à manutenção do padrão nuclear burguês de família na constituição das futuras famílias adotivas. São casais formalmente casados os que mais encontramos no Cadastro Nacional de Adoção referente à comarca de Volta Redonda.

Cabe, porém, um questionamento. Esse número é reflexo real de que casais formalmente casados são os que mais entram com o pedido de habilitação ou eles são os que mais são habilitados?

Outro aspecto interessante do perfil construído demonstra que os habilitados são, na maioria, pertencentes ao grupo que o senso comum chamaria de "bem sucedidos socialmente". Escolaridade alta, boa renda e inserção ocupacional.

Cabe novamente a mesma questão: solteiros ou casais incluídos nesse grupo são os que mais entram com o pedido de habilitação para adoção ou são os que mais são avaliados positivamente para isso?

Sobre isso, tentamos identificar na pesquisa o número de processos de habilitação indeferidos. Só conseguimos identificar dois processos, mas sem análise de conteúdo sobre os motivos, já que eles já estão arquivados. Diante disso, nova hipótese se impõe: os interessados na habilitação para adoção que não correspondem ao perfil dos dados aqui apresentados, ao participarem dos primeiros atendimentos (antes de formalizarem o processo de habilitação), desistem de entrar com esse pedido após as primeiras informações e dúvidas esclarecidas? Sobre esse quantitativo de "desistentes" não foi possível averiguar, pois não há registros a respeito.

Os dados nos mostram ainda a tendência de que habilitados para adoção não possuem filhos biológicos, numa clara e já conhecida experiência de que a filiação jurídica da adoção é substitutiva à filiação biológica.

As análises do tempo médio de relação e de média de idade dos habilitados nos sugerem, de certo modo, um aguardo de definições e projetos de vida antes da decisão pela adoção. Vimos que a maioria já tem estabilidade de trabalho e renda e de relação, indicadores que mostram, possivelmente, a segurança financeira e familiar como um fator predominante para a decisão em adotar uma criança ou adolescente.

Com referência ao tempo médio de duração do processo de habilitação, confirma-se parcialmente ao que é difundido na mídia e nos debates sobre o tema: é preciso paciência para finalização do processo. 0 tempo dedicado ao estudo social e psicológico é justificado pela necessidade de avaliação coerente, motivadora de reflexões e entendimento do significado da adoção. Contudo, soma-se um tempo significativo de espera dos ritos administrativos e burocráticos.

Diante dos dados colhidos e sistematizados, podemos inferir que os habilitados para adoção na comarca de Volta Redonda correspondem ao que entendemos como modelo de família tradicional, pertencentes à classe média e que encontram na adoção a possibilidade de exercerem a maternagem/ paternagem. 


\section{REFERÊNCIAS}

BADINTER. E. Um amor conquistado: o mito do amor materno. Rio de Janeiro: editora Nova Fronteira,1985.

Lei 8069 de 1990, Estatuto da criança e do adolescente. Brasília: DF, 1990.

Constituição federal do brasil. Brasília: DF, 1988.

Lei Ordinária Nº 12.010, Nova lei de adoção. Brasília: DF, 2009.

Plano Nacional de Promoção, Proteção e Defesa do Direito de Crianças e Adolescentes à Convivência Familiar e Comunitária. Secretaria Especial de Direitos Humanos da Presidência da República. DF, 2006.

CHODOROW, Nancy. Psicanálise da maternidade: uma crítica a Freud a partir da mulher. Rio de Janeiro: Editora Rosa dos Tempos, 1990.

CONSELHO NACIONAL DE JUSTIÇA. Resolução N 175, de 14 de maio de 2013.

COUTINHO, Maria Lúcia Rocha. Transmissão geracional e família na contemporaneidade: família e geração. Rio de Janeiro: Editora FVG,2006.

FERREIRA, L. A. M , Adoção: guia prático doutrinário e processual com alterações da Lei n.12010, de 3/8/2009. São Paulo: Cortez, 2010.

FONSECA, Claudia; CARDARELLO, Andrea. Família e parentesco In: MORAES Amaury César (Coordenação. Sociologia : ensino médio. Brasília, Ministério da Educação, Secretaria de Educação Básica, 2010. 304 p. (Coleção Explorando o Ensino ; v. 15).

Sexualidade, família e legalidade: questionando fronteiras. In: Novas legalidades e democratização da vida social: família, sexualidade e aborto. Maria Betânia Ávila, Ana Paula Portella e Verônica Ferreira (Orgs.). Rio de Janeiro: Gramond, 2005.

LAKATO, Eva Maria; MARCONI, Marina de Andrade. Fundamentos de metodologia científica. 5. Ed.. São Paulo: Atlas, 2003.

PLANO MATER. Ato Executivo 4065 de 2009. Regulamenta os procedimentos da comissão estadual judiciária de adoção do Estado do RJ e dá outras providências. Estado do Rio de Janeiro, Poder Judiciário, 2009.

RIZINI, Irene; RIZINI, Irma; NAIFF, Luciene e BAPTISTA, Rachel (coord). Acolhendo crianças e adolescentes: experiências de promoção do direito à convivência familiar e comunitária no Brasil. São Paulo: Cortez 2. Ed; Brasília, DF:UNICEF; CIESPI; Rio de Janeiro, RJ: PUC Rio, 2007.

SIMANSKI,Heloísa. Viver em família como experiência de cuidado mútuo: desafios de um mundo em mudança. Serviço Social e Sociedade, Revista Quadrimestral de Serviço Social, ano XXIII,n¹, Setembro de 2002. 